\title{
Paraplegia Following Intraaortic Balloon Circulatory Assistance
}

\author{
Anderson Benício, Luiz Felipe P. Moreira, José Otávio Costa Auler Jr, \\ Noedir Antônio Groppo Stolf, Adib Domingos Jatene
}

\author{
São Paulo, SP - Brazil
}

\begin{abstract}
Intraaortic balloon counterpulsation is frequently used in patients experiencing severe ventricular dysfunction following maximal drug therapy. However, even with the improvement of percutaneous insertion techniques, the procedure has always been followed by vascular, infectious, and neurological complications. This article describes a case of paraplegia due to intraaortic balloon counterpulsation in the postoperative period of cardiac surgery.
\end{abstract}

Intraaortic balloon counterpulsation has been frequently and successfully used as a mechanical circulatory assistance device in cases of left ventricular failure. Several complications are associated with this procedure, despite the development and evolution that the device underwent since its creation.

Some complications of the intraaortic balloon counterpulsation can be easily managed, such as the hematomas and localized infections ${ }^{1}$. However, there are some complications that are more severe and even irreversible, even though rarer $^{2-6}$.

We report a case of paraplegia following intraaortic balloon assistance and a concise literature review.

\section{Case Report}

The patient is a 49-year-old white male, who presented with acute myocardial infarction in the inferolaterodorsal region. He underwent successful thrombolytic treatment and evolued in Killip class I. On the fifteenth day after infarction, however, he experienced angina. On the following day, he underwent myocardial revascularization, during which the following grafts were performed: left internal thoracic artery for the anterior interventricular artery and saphenous bypasses for the left marginal branch and the right coronary artery, in which an endarterectomy was performed. The operation was uneventful.

Instituto do Coração do Hospital das Clínicas - FMUSP

Mailing adress: Anderson Benício - Incor - Av. Dr. Enéas de Carvalho aguiar, 44 $2^{\circ}$ andar - Div. de Cirurgia Torácica e Cardiovasculaar - 05403-000 - São Paulo - SP.
A few hours after admission to the intensive care unit, the patient experienced total atrioventricular block with significant hemodymanic compromise, thus requiring placement of a temporary epicardial pacemaker. He went into cardiopulmonary arrest, which was successfully reversed with normal resuscitation maneuvers. Despite therapy, he developed significant hemodynamic instability, requiring mechanical circulatory assistance with intraaortic balloon counterpulsation (Datascope $40 \mathrm{~mL} 9.5$ Fr, Datascope Corp., Fairfield, New Jersey, USA), on the first postoperative day. On the fourth postoperative day, due to improvement of clinical and hemodynamic status, the device was withdrawn. Its permanence was estimated in 84 hours.

Despite the presence of strong pedal and posterior tibial pulses and good perfusion bilaterally, the patient developed paralysis of the lower limbs, on the fourth postoperative day. Head, thoracic and lumbar spine computed tomographic scans were performed, but they showed no abnormality that could explain the paraplegia.

The patient was finally discharged from the hospital in the sixth postoperative month, after being treated successfully for several infectious, respiratory, and renal (requiring dialysis) complications, and many surgeries for decubitus ulcer correction.

Currently, after a postoperative follow-up of 12 months, he is being treated on an outpatient basis and is asymptomatic from the cardiovascular standpoint. However, despite regular physical therapy, he has shown no improvement in the motor and sensitive condition of his lower limbs.

\section{Discussion}

Intraaortic balloon counterpulsation has become more frequently used in clinical management as a circulatory assistance device. However, many studies ${ }^{1-6}$ report complications related to the procedure (table I). The most frequent vascular complications reported are thromboembolism, absence of distal pulse, pain, dissections, ischemia, and even gangrene and amputation of limbs. In addition to the vascular complications, there are infectious ones, all occurring with similar frequency with signs of fever, local infection, and bacteremia. Less frequently, bleeding also occurs. Other less frequent complications, though not so 


\begin{tabular}{|c|c|c|c|c|c|c|}
\hline Authors & Age/Gender & Surgery & Indication & Complication & Evolution & Autopsy \\
\hline Tyras and Willman, 1978 & $61 / \mathrm{M}$ & MR & Intraop & ARF & Death & IH of TA and SCN \\
\hline \multirow[t]{3}{*}{ Macoviak et al, 1980} & $57 / \mathrm{F}$ & MR & Postop & Sepsis & Death & Denied \\
\hline & $60 / \mathrm{M}$ & MR & Intraop & ARF & Death & Denied \\
\hline & $34 / \mathrm{M}$ & MR & Intraop & Sepsis & Death & No signs of SCN \\
\hline Criado et al, 1979 & $32 / \mathrm{F}$ & MiVC & Intraop & AMI/ARF & PR & \multirow{7}{*}{$\begin{array}{c}\text { Denied } \\
\text { CT and } \\
\text { negative aortography } \\
\text { Mesenteric, medullary and } \\
\text { abdominal embolism }\end{array}$} \\
\hline \multirow[t]{2}{*}{ Singh et al, 1983} & $46 / \mathrm{M}$ & & Shock & & Reversion & \\
\hline & $66 / F$ & & Shock & & Death & \\
\hline \multirow[t]{2}{*}{ Rose et al, 1984} & \multirow[t]{2}{*}{$67 / \mathrm{M}$} & \multirow[t]{2}{*}{ MR } & UA & \multirow[t]{2}{*}{$\mathrm{PE}$} & No & \\
\hline & & & Preop & & alteration & \\
\hline Harris et al, 1986 & $72 / \mathrm{M}$ & $\begin{array}{c}\text { MR and } \\
\text { ASD }\end{array}$ & Intraop & $\begin{array}{c}\text { ARF/AMI } \\
\text { MI }\end{array}$ & Death & \\
\hline Riggle e Oddi, 1989 & $59 / \mathrm{M}$ & MR & Preop & MOSF & Death & \\
\hline Orr et al, 1989 & $41 / \mathrm{F}$ & MR & Postop & $\begin{array}{c}\text { ARF, MI, } \\
\text { ARDS }\end{array}$ & $\begin{array}{c}\text { No } \\
\text { alteration }\end{array}$ & \\
\hline \multirow{2}{*}{$\begin{array}{l}\text { Stavridis e } \\
\text { O'Riordan, } 1995 \\
\text { Scott et al, } 1984\end{array}$} & 69/M & MR & Intraop & $\begin{array}{l}\text { Peripheral } \\
\text { embolism }\end{array}$ & $\begin{array}{c}\text { No } \\
\text { alteration }\end{array}$ & \\
\hline & $69 / \mathrm{M}$ & MR & Preop & $\begin{array}{l}\text { Post-AMI } \\
\text { VSD }\end{array}$ & $\begin{array}{c}\mathrm{No} \\
\text { alteration }\end{array}$ & \\
\hline Seifert e Silverman 1986 & $72 / \mathrm{F}$ & MR & Preop & \multirow[t]{2}{*}{$\mathrm{AD}$} & PR & \\
\hline Hurlé et al 1986 & $61 / \mathrm{M}$ & MR & Preop & & No & \\
\hline Beholz et al 1998 & $66 / \mathrm{M}$ & MR & Intraop & ARF & $\begin{array}{l}\text { alteration } \\
\quad \text { No } \\
\text { alteration }\end{array}$ & $\mathrm{SCN}$ \\
\hline $\begin{array}{l}\text { AD- aorta dissection; AM } \\
\text { hematoma; Intraop- intrao } \\
\text { MOSF- multiple organs a } \\
\text { SCN- spinal cord necrosis; }\end{array}$ & $\begin{array}{l}\text { ite myocardia } \\
\text { ve; VSD- ven } \\
\text { stems failure; } \\
\text { thoracic aorta }\end{array}$ & $\begin{array}{l}\text { n; ARF- } \\
\text { eptal def } \\
\text { postoper } \\
\text { stable an }\end{array}$ & $\begin{array}{l}\text { nal failure } \\
\text { mesenteric } \\
\text { - partial } \mathrm{r} \\
\text { pulmonar }\end{array}$ & $\begin{array}{l}\text { trial septal de } \\
\text { n; MiVC- mit } \\
\text { Preop- preope } \\
\text { sm. }\end{array}$ & $\begin{array}{l}\text { - computer } \\
\text { e change; } \mathrm{N} \\
\text { ARDS- adu }\end{array}$ & $\begin{array}{l}\text { omography; IH- intramural } \\
\text { nyocardial revascularization; } \\
\text { spiratory distress syndrome; }\end{array}$ \\
\hline
\end{tabular}

severe, are migration and retention of the balloon. A devastating complication, however, is being reported more frequently, despite its rareness. It is paraplegia associated with intraaortic balloon counterpulsation.

Currently 16 reports of paraplegia associated with intraaortic balloon counterpulsation have been reported in the literature (table I). In a study by Macoviak et al ${ }^{1}$, the incidence of complications related to the device considered is smaller when it is intraoperatively inserted through the ascending aorta $(4 \%)$ than through the femoral or iliac arteries $(25 \%)$. In this same study, in a five-year follow-up, the rate of paraplegia associated with the use of the balloon was $1.7 \%$. Two pathophysiological mechanisms have been considered for this rare complication. The first suggests that an aortic dissection or a hematoma of the adventitial layer can lead to occlusion of a major radicular branch of the spinal cord where an infarct can result. The second suggests that a local occlusion of the Adamkiewicz artery with atheromatous material could occur without a traumatic localized dissection of the aorta or hematoma. A common factor in the majority of cases is the presence of atheromatous disease of the aorta.

Stavridis et $\mathrm{al}^{3}$ performed postmortem examination on 4 out of 7 deaths. One autopsy revealed intramural hematoma under the thoracic aorta adventitia and in six pairs of intercostal arteries with spinal cord infarct. Another autopsy revealed embolic phenomena of atheromatous material in medullary and mesenteric arteries and also in the arteries of abdominal organs, as well. The third autopsy showed necrosis of the spinal cord with no evidence of aortic dissection or hemato- ma. And finally, in the last autopsy, the examination did not reveal the cause of paraplegia.

In the same study, five patients had the device preoperatively placed, six had it inserted during surgery (five due to difficulty in extracorporeal circulation weaning and one after induction), two had it placed due to postoperative hemodynamic instability, and two received the device without surgery. Among the patients who showed clinical improvement, only one had complete reversion of paraplegia.

The incidence of mechanical circulatory assistance using intraaortic balloon counterpulsation in our service is approximately $6 \%$ per year, considering an average of 1,400 patients operated every year. The only patient who developed paraplegia as a result of this procedure is the one that is the focus of this paper.

The intraaortic balloon provides an excellent hemodynamic support, constituting an important therapeutic option. However, the existence of peripheral vascular disease, a history of intermittent claudication, and reduction or absence of peripheral pulses in the lower limbs are significant risk factors for vascular complications. In a parallel manner, the mode of insertion of the device also results in significant incidence of vascular complications that could be partially avoided with the introduction of the intraaortic balloon by the dissection of the femoral artery. Another method that has a low incidence of complications in a patient with atheromatous disease of the abdominal aorta, the iliac arteries, or both is the placement of the device during surgery into the ascending aorta or in the distal portion of the arch. 


\section{References}

1. Macoviak J, Stephenson LW, Edmunds LHJR, Harken A, MacVaugh H III. The intraaortic balloon pump: An analysis of five years'experience. Ann Thorac Surg 1980; 29: 451-8.

2. Criado A, Agosti J, Horno R, Jimenez C. Paraplegia following balloon assistance after cardiac surgery. Scand J Thor Cardiovasc Surg 1981; 15: 103-4.

3. Stavridis GT, O'Riordan JB. Paraplegia as a result of intra-aortic balloon counterpulsation. J Cardiovasc Surg 1995; 36: 177-9.
4. Seifert PE, Silverman NA. Late paraplegia resulting from intraaortic balloon pump. Ann Thorac Surg 1986; 41: 700.

5. Hurlé A, Llamas P, Meseguer J, Casillas JA. Paraplegia complicating intraaortic balloon pumping. Ann Thorac Surg 1997; 63: 1217-18.

6. Beholz A, Braum J, Ansorge K, Wollert HG, Eckel L. Paraplegia caused by aortic dissection after intraaortic balloon pump assistance. Ann Thorac Surg 1998; 65: 603-4. 